\title{
Estudo da viabilidade de sementes de brassavola tuberculata hook. em função do período de armazenamento, tempo de cultivo e tratamento pré-germinativo(i)
}

\author{
YARA BRITO CHAIM JARDIM ROSA(2); GILMAR AUGUSTO MARQUES JÚNIOR (2); JACKELINE SCHULTZ SOARES(2); \\ DEREK BRITO CHAIM JARDIM ROSA(2); MARICHEL CANAZZA DE MACEDO(2); ALINE MOHAMUD ABRÃO CEZAR(2)
}

\begin{abstract}
RESUMO
A germinação assimbiótica é um dos principais métodos de multiplicação de Orchidaceae. Entretanto, a viabilidade das sementes dessa família botânica é susceptível a fatores bióticos e abióticos que podem inviabilizar esse processo. Objetivouse com este trabalho avaliar o efeito do período de armazenamento, de tratamento pré-germinativo e do tempo de cultivo sobre a porcentagem de germinação das sementes de Brassavola tuberculata e também verificar se o procedimento amostral do teste de tetrazólio é eficaz para predizer a porcentagem de germinação da espécie. O delineamento experimental utilizado foi o inteiramente casualizado e os tratamentos foram arranjados em esquema de parcelas sub-subdivididas, sendo alocados na parcela os tempos de armazenamento (até 360 dias), na subparcela os tratamentos pré-germinativos (embebição com água destilada ou com $4 \mathrm{mg} \mathrm{L}^{-1}$ de $\mathrm{GA}_{3}$ ) e na sub-subparcela os tempos de cultivo (15 ou 30 dias), com quatro repetições. $\mathrm{O}$ tratamento pré-germinativo com $\mathrm{GA}_{3}$ propicia aumento na porcentagem de germinação de $B$. tuberculata somente até os 130 dias de armazenamento. Sementes não submetidas a este fitorregulador podem ser armazenadas por 360 dias com porcentagem de germinação acima de 50\%. B. tuberculata apresenta maior porcentagem de germinação aos 30 dias de cultivo tanto para sementes submetidas a tratamento pré-germinativo quanto para as não submetidas e, o teste de tetrazólio, efetuado de maneira amostral, pode ser utilizado apenas para indicação da viabilidade das sementes armazenadas. Palavras-chave: Teste de viabilidade, Cultivo in vitro, Orchidaceae.
\end{abstract}

ABSTRACT

Study of seed viability of brassavola tuberculata hook. as a function of storage period, cultivation time and pregermination treatments

\begin{abstract}
Asymbiotic germination is one of the main methods of multiplication of Orchidaceae. However, the viability of the seeds of this botanical family is susceptible to biotic and abiotic factors that can make impracticable this process. The aim of this study was to evaluate the effect of the storage period, pre-germination treatments and cultivation time on the germination of seeds Brassavola tuberculata and also check if the sampling procedure of the tetrazolium test is effective in predicting germination percentage of the species. The experimental design was completely randomized and treatments were arranged in a split split plots being allocated in plot storage times (up to 360 days), the sub-plot the pre-germination treatments (soaking in distilled water or with $4 \mathrm{mg} \mathrm{L}^{-1} \mathrm{GA}_{3}$ ) and the sub-subplot culture times (15 or 30 days), with four replications. The pre-germination treatment with $\mathrm{GA}_{3}$ provides increase in the germination percentage of $B$. tuberculata only until 130 days of storage. Seeds not submitted to this phytoregulator can be stored for 360 days with germination percentage over $50 \%$. B. tuberculata has a higher germination percentage at 30 days of cultivation as for seeds submitted to pregerminative treatment as not. And the tetrazolium test, sampling performed only can be used for indication of the viability of stored seeds. Keywords: Viability test, In vitro culture, Orchidaceae.
\end{abstract}

\section{INTRODUÇÃO}

Embora o mercado brasileiro de flores seja caracterizado pelo baixo consumo per capita (JUNQUEIRA e PEETZ, 2008), as plantas da família Orchidaceae são muito apreciadas por colecionadores e comerciantes devido à beleza de suas flores (STEFANELLO et al., 2009). Em decorrência disso, a prática do extrativismo, aliada ao avanço da agricultura tem retirado as orquídeas dos seus habitats e destruído os ecossistemas, dificultando sua sobrevivência e reprodução (IMES, 1997). Nesse sentido, a conservação de sementes e a produção de mudas de orquídeas são alternativas de preservação (MELLO, 2000), podendo ser utilizadas tanto em programas de reintrodução quanto para a comercialização (BACH e CASTRO, 2004).
A maioria das orquídeas apresenta floração anual e sua reprodução requer polinizadores específicos (DRESSLER, 1993) o que reduz o número de frutos produzidos naturalmente. Em vista disso, um método eficaz de conservação de suas sementes é necessário para a produção contínua de mudas. A prática da dessecação seguida de baixas temperaturas tem sido utilizada com maior ou menor eficiência para a conservação de sementes de Orchidaceae (PRITCHARD e SEATON, 1993; PRITCHARD et al., 1999; MELLO, 2000).

A avaliação da qualidade das sementes recém-colhidas ou armazenadas requer a utilização de testes que permitam o uso ou o descarte do material analisado. Segundo KRZYZANOWISKI et al. (1999), a aplicação do teste de tetrazólio é uma alternativa rápida e de baixo custo para

\footnotetext{
(1) Recebido em 29/10/2012 e aceito para publicação em 02/07/2012

(2) FCA/UFGD. Rodovia Dourados - Itahum, km 12 CEP: 79804-970 Dourados - MS, e-mail: yararosa@ufgd.edu.br
} 
avaliação do potencial fisiológico das sementes. Esse teste tem sido utilizado com êxito para a avaliação de sementes de Orchidaceae.

O teste de tetrazólio reflete a atividade das enzimas desidrogenases envolvidas no processo de respiração. Pela hidrogenação do 2, 3, 5 trifenil cloreto de tetrazólio é produzida, nas células vivas, uma substância vermelha, estável e não difusível, o trifenil formazan. Isto torna possível distinguir as partes vivas, coloridas de vermelho, daquelas mortas que não colorem (OLIVEIRA et al., 2005). Como esta reação se processa no interior das células vivas e o composto não se difunde, há nítida separação dos tecidos vivos e coloridos que respiram, daqueles mortos e que não colorem (BRASIL, 2009).

O teste apresenta vantagens tais como: não é afetado por diversas condições que podem alterar os resultados do teste padrão de germinação, como a presença de fungos; enfoca as condições físicas e fisiológicas do embrião de cada semente individualmente; permite rápida avaliação da viabilidade e requer equipamento simples e barato (FRANÇA NETO et al., 1998; FRANÇA NETO, 1999).

Tratamentos pré-germinativos, com a utilização de reguladores de crescimento visando auxiliar nos processos de germinação e desenvolvimento de plântulas in vitro, têm sido relatados para diversas espécies (MIYOSHI e MII, 1995; SANTOS et al., 2007, MACEDO et al., 2011), entretanto com resultados contraditórios.

SANTOS et al. (2007) relatam que a utilização de 1,0 $\mathrm{mg} \mathrm{L}^{-1}$ de ácido giberélico, em tratamento pré-germinativo, propiciou o aumento no número de plântulas formadas, enquanto que as concentrações de 2,0 e 5,0 $\mathrm{mg} \mathrm{L}^{-1}$ elevaram a porcentagem de protocormos com gemas de Cattleya bicolor germinada in vitro. Em contrapartida, MACEDO et al. (2011) salientam que o aumento da concentração de GA até $4 \mathrm{mg} \mathrm{L}^{-1}$ e do tempo de embebição das sementes de Schomburgkia crispa até 120 minutos nesse regulador, reduziram a porcentagem de germinação de $95,1 \%$ para $22,84 \%$.

Brassavola tuberculata Hook é uma espécie que ocorre no cerrado, caatinga e mata atlântica se distribuindo nos estados de Tocantins, Alagoas, Bahia, Paraíba, Pernambuco, Sergipe, Minas Gerais, Rio de Janeiro, São Paulo, Paraná, Santa Catarina, Rio Grande do Sul (BARROS et al., 2013) e Mato Grosso do Sul (RECH et al., 2011). Grande tem sido o interesse de colecionadores, melhoristas e programas de preservação por essa espécie, que se destaca por seu elevado valor florístico e rusticidade, sendo que seu cruzamento com os gêneros Cattleya e Sophronitis (EIGELDINGER e MURPHY, 1972), origina plantas com características morfológicas mais interessantes que os parentais.

Em vista do exposto, este trabalho foi desenvolvido para: 1) avaliar o efeito do período de armazenamento, de tratamento pré-germinativo e do tempo de cultivo sobre a porcentagem de germinação das sementes de Brassavola tuberculata; 2) verificar se o procedimento amostral do teste de tetrazólio é eficaz para predizer a porcentagem de germinação de $B$. Tuberculata.

\section{MATERIAL E MÉTODOS}

O experimento foi realizado no Laboratório de Cultivo in vitro da Faculdade de Ciências Agrárias (FCA) da Uni- versidade Federal da Grande Dourados (UFGD). Foram utilizadas como material de estudo sementes de Brassavola tuberculata, provenientes de uma reserva legal do município de Dourados - MS, localizada nas coordenadas $22^{\circ} 24^{\prime} \mathrm{S}$ e $54^{\circ} 46^{\prime} \mathrm{W}$, com altitude média de $327 \mathrm{~m}$. As médias anuais de temperatura do ar máxima e mínima são de 24 e $20^{\circ} \mathrm{C}$, respectivamente, com precipitação total anual entre $1250 \mathrm{e}$ $1500 \mathrm{~mm}$. O clima regional é do tipo Cwa mesotérmico úmido, segundo a classificação de KÖPPEN (1948).

Cápsulas fechadas de $B$. tuberculata foram coletadas sete meses após a polinização e, as sementes provenientes destas, foram retiradas, homogeneizadas, pesadas e mantidas em dessecador, com sílica gel, por 15 dias, em ambiente provido de luz fluorescente branca $\left(6,75 \mu \mathrm{mol} \mathrm{m} \mathrm{m}^{-2} \mathrm{~s}^{-1}\right)$, com fotoperíodo e temperatura controlados $\left(12 \mathrm{~h} ; 22 \pm 2^{\circ} \mathrm{C}\right)$. Após este período as sementes foram divididas em amostras de $5 \mathrm{mg}$, embaladas em papel alumínio e acondicionadas em frascos de polipropileno opaco providos de tampa com sílica gel e armazenadas, sob refrigeração, em temperatura de $5 \pm 2{ }^{\circ} \mathrm{C}$ por 360 dias.

Imediatamente após o período de dessecação e, a cada 15 dias após o armazenamento, a viabilidade das sementes foi avaliada mediante o teste de tetrazólio. Para a determinação da viabilidade de $B$. tuberculata, quatro amostras de $5 \mathrm{mg}$ foram colocadas em tubos de ensaio e cada uma delas recebeu $3 \mathrm{~mL}$ de solução aquosa de cloreto de trifenil tetrazólio $0,5 \%$. As suspensões de sementes foram acondicionadas em ambiente desprovido de luz a $25 \pm 2{ }^{\circ} \mathrm{C}$. Após 24 horas as suspensões de tetrazólio foram acrescidas de $7 \mathrm{~mL}$ de água destilada e agitadas, sendo pipetado $1 \mathrm{~mL}$ para identificação e contagem de sementes viáveis, em câmara de Peters, com o auxílio de um microscópio estereoscópico.

Foi contado o número das sementes portadoras de embriões completamente coloridos de carmim, o número de sementes com embriões parcialmente corados e os incolores, além das sementes desprovidas de embriões, sendo as três últimas consideradas inviáveis. A partir dessa contagem foi determinado o percentual de sementes viáveis $(\% \mathrm{SV})$ pela seguinte fórmula: $\% \mathrm{SV}=\left(\mathrm{N}^{\circ}\right.$ de sementes com embriões carmim x 100)/ No total de sementes observadas. A coloração das sementes submetidas ao teste de tetrazólio foi registrada por meio de fotografias obtidas com câmera adaptada a uma ocular do microscópio estereoscópico.

Para confirmação dos resultados obtidos no teste de tetrazólio e para a avaliação do tratamento pré-germinativo com ácido giberélico, imediatamente após o período de dessecação e depois, a cada 15 dias durante o período de armazenamento, duas amostras de sementes, de $5 \mathrm{mg}$ cada, foram utilizadas para a semeadura in vitro. Cada porção de sementes foi transferida para Erlenmeyer de $250 \mathrm{~mL}$ e embebidas em $50 \mathrm{~mL}$ de água destilada estéril, por 15 minutos, no interior da câmara de fluxo laminar. Em seguida, a água de embebição foi descartada e as suspensões de sementes foram desinfestadas, por 15 minutos com uma solução composta por 3 $\mathrm{mL}$ de hipoclorito de sódio (2,5\%) e $6 \mathrm{~mL}$ de água destilada estéril (CAMPOS, 2002). Decorrido esse tempo, as sementes receberam tríplice lavagem com água estéril. Na sequência, procedeu-se o tratamento pré-germinativo, sendo que uma porção de sementes foi embebida em $10 \mathrm{~mL}$ de água estéril e a outra em $10 \mathrm{~mL}$ de solução de ácido giberélico $\left(4 \mathrm{mg} \mathrm{L}^{-1}\right)$ por 15 minutos. Decorrido esse período, as soluções de em- 
bebição foram descartadas e as sementes receberam $20 \mathrm{~mL}$ de água estéril para a realização da semeadura.

O meio de cultura utilizado foi o MURASHIGE e SKOOG, 1962 (MS) na metade de sua concentração de sais e vitaminas, acrescido de $25 \mathrm{~g} \mathrm{~L}^{-1}$ de sacarose e $5,5 \mathrm{~g} \mathrm{~L}^{-1}$ de ágar bacteriológico, sendo seu $\mathrm{pH}$ ajustado para 5,5 $\pm 0,1 \mathrm{com}$ $\mathrm{KOH}(1 \mathrm{M})$. A quantidade de meio de cultura por frasco foi de $10 \mathrm{~mL}$, sendo utilizados frascos plásticos transparentes, providos de tampas, com capacidade para $50 \mathrm{~mL}$. Após a distribuição dos meios nutritivos, os frascos passaram por esterilização em autoclave a $121^{\circ} \mathrm{C}$ e à pressão de $1,05 \mathrm{~kg}$ $\mathrm{cm}^{-2}$, por 20 minutos.

Após o resfriamento do meio de cultura, procedeu-se a semeadura in vitro, em ambiente asséptico. Foi pipetado 1 mL da suspensão de sementes em cada frasco de cultivo. Após a semeadura, os frascos foram acondicionados em sala de crescimento com fotoperíodo de 12 horas sob luz fluorescente branca $\left(13,51 \mu \mathrm{mol} \mathrm{m} \mathrm{m}^{-2} \mathrm{~s}^{-1}\right)$ e temperatura de $25 \pm 2{ }^{\circ} \mathrm{C}$, permanecendo nessas condições por 30 dias.

Para cada época de semeadura a porcentagem de germinação foi avaliada aos 15 e 30 dias após a semeadura nos dois tratamentos pré-germinativos. Para isso foram adicionados em cada frasco, $10 \mathrm{~mL}$ de água destilada, e após a agitação manual a suspensão de sementes foi vertida em placas Petri e, com o auxílio de um microscópio estereoscópico, contou-se o número total de sementes observadas e o número de sementes intumescidas. A porcentagem de germinação foi calculada utilizando-se a seguinte fórmula: Germinação (\%) $=\left(\mathrm{N}^{o}\right.$ de sementes intumescidas $\left.\mathrm{x} 100\right) / \mathrm{N}^{\circ}$ total de sementes observadas.

Foi utilizado o delineamento experimental inteiramente casualizado, com quatro repetições.

Para avaliação do número de sementes viáveis os tratamentos foram constituídos do tempo de armazenamento, sendo que cada repetição foi constituída de três leituras.

Para avaliação do tempo de armazenamento dos tratamentos pré-germinativos e do tempo de cultivo sobre a porcentagem de germinação, os tratamentos foram arranjados em esquema de parcelas sub-subdivididas, sendo as parcelas os tempos de armazenamento, as subparcelas os tratamentos pré-germinativos e as sub-subparcelas os tempos de cultivo (15 e 30 dias), sendo cada repetição constituída por dois frascos de cultura.

Os dados foram submetidos à análise de variância pelo teste $\mathrm{F}$ até $5 \%$ de probabilidade. Os fatores qualitativos, quando significativos, foram comparados por teste de médias até $5 \%$ de probabilidade e os quantitativos por regressão, com a utilização do aplicativo computacional SISVAR 5.3 (FERREIRA, 2010).

\section{RESULTADOS E DISCUSSÃO}

Houve efeito significativo do tempo de armazenamento $(\mathrm{p}<0,01)$ sobre a porcentagem de sementes inviáveis $(\% \mathrm{SI})$ e das viáveis ( $\% \mathrm{SV})$.

À medida que o tempo de armazenamento aumentou houve decréscimo na \%SV, sendo que aos 360 dias (final do período experimental) elas constituíam cerca de 40,0\% (valor calculado) apresentando uma perda de viabilidade em torno de $27 \%$ ou seja, uma taxa de redução mensal de viabilidade de 2,3\% (Figura 1).
A perda de viabilidade de sementes de Orchidaceae em função do período de armazenamento foi relatada por ALVAREZ-PARDO e FERREIRA (2006) que, armazenando sementes a $5 \pm 1{ }^{\circ} \mathrm{C}$, observaram esse efeito para as 16 espécies estudadas ao longo de 30 meses. Entretanto, os autores relatam que as sementes de Maxillaria picta e Cattleya labiata perderam quase totalmente a viabilidade após esse período.

Os resultados observados nesse experimento e os relatados por ALVAREZ-PARDO e FERREIRA (2006) quanto à variação da porcentagem de viabilidade de sementes armazenadas, sob mesmas condições, permite inferir que, cada espécie responde de maneira diferenciada às condições e ao período de armazenamento, sendo que essas respostas podem inclusive variar dentro de uma mesma espécie em função das condições nas quais aos frutos foram produzidos e do seu estágio de maturação, assim como dos processos utilizados na pós-coleta antecedentes ao armazenamento.

Houve efeito isolado e conjunto do tempo de armazenamento, período de cultivo e utilização de $\mathrm{GA}_{3}$ sobre a porcentagem de sementes germinadas de $B$. tuberculata e os resultados decorrentes da interação dos três fatores estudados são apresentados na Figura 2.

Foram registrados efeitos significativos do tempo de armazenamento apenas quando foi utilizada a embebição das sementes com $\mathrm{GA}_{3}$. Com a utilização do regulador de crescimento, as maiores porcentagens de geminação foram observadas em tempo de cultivo de 30 dias e até o período de armazenamento de 180 dias. A partir dos 180 dias de armazenamento, independentemente do tempo de cultivo, as porcentagens de germinação das sementes embebidas com $\mathrm{GA}_{3}$, não diferiram estatisticamente entre si (Figura 2).

Quando não se utilizou $\mathrm{GA}_{3}$, o tempo de armazenamento não influenciou a porcentagem de germinação, que foi maior no tempo de cultivo de 30 dias $(71,8 \%)$, enquanto que aos 15 dias de cultivo foi de $63,8 \%$. As sementes tratadas com $\mathrm{GA}_{3}$ apresentaram porcentagem de germinação superior às não tratadas apenas quando o período de armazenamento foi de no máximo 166 e 130 dias, respectivamente para períodos de cultivo de 15 e 30 dias (Figura 2).

Segundo HARTMANN et al. (1997), considera-se como índice de armazenabilidade a capacidade relativa da semente germinar, no mínimo em 50\%, após ser armazenada em condições ambientais favoráveis por um determinado período de tempo, sendo consideradas de categoria 1 aquelas com esta capacidade por um a dois anos; categoria 2, aquelas armazenáveis por três a cinco anos, e categoria 3 , as armazenáveis por mais de cinco anos . De acordo com essa classificação, as sementes de $B$. tuberculata são enquadradas em categoria 1 neste estudo, se não receberem o tratamento pré-germinativo com $\mathrm{GA}_{3}$. Se as sementes dessa espécie forem receber tratamento pré-germinativo com GA3 após o período de armazenamento, elas só poderão ser armazenadas por até 250 dias para apresentarem porcentagem de germinação de no mínimo 50\%. Todavia, esse procedimento não possibilita seu enquadramento em nenhuma das categorias relacionadas por HARTMANN et al. (1997).

MELLO (2000), ao armazenar sementes de Cyrtopodium spp., Epidendrum nocturnum e de um acesso de Schomburgkia crispa por um ano a $5^{\circ} \mathrm{C}$, obteve porcentagem de germinação acima de $60 \%$, permitindo o enquadramento 


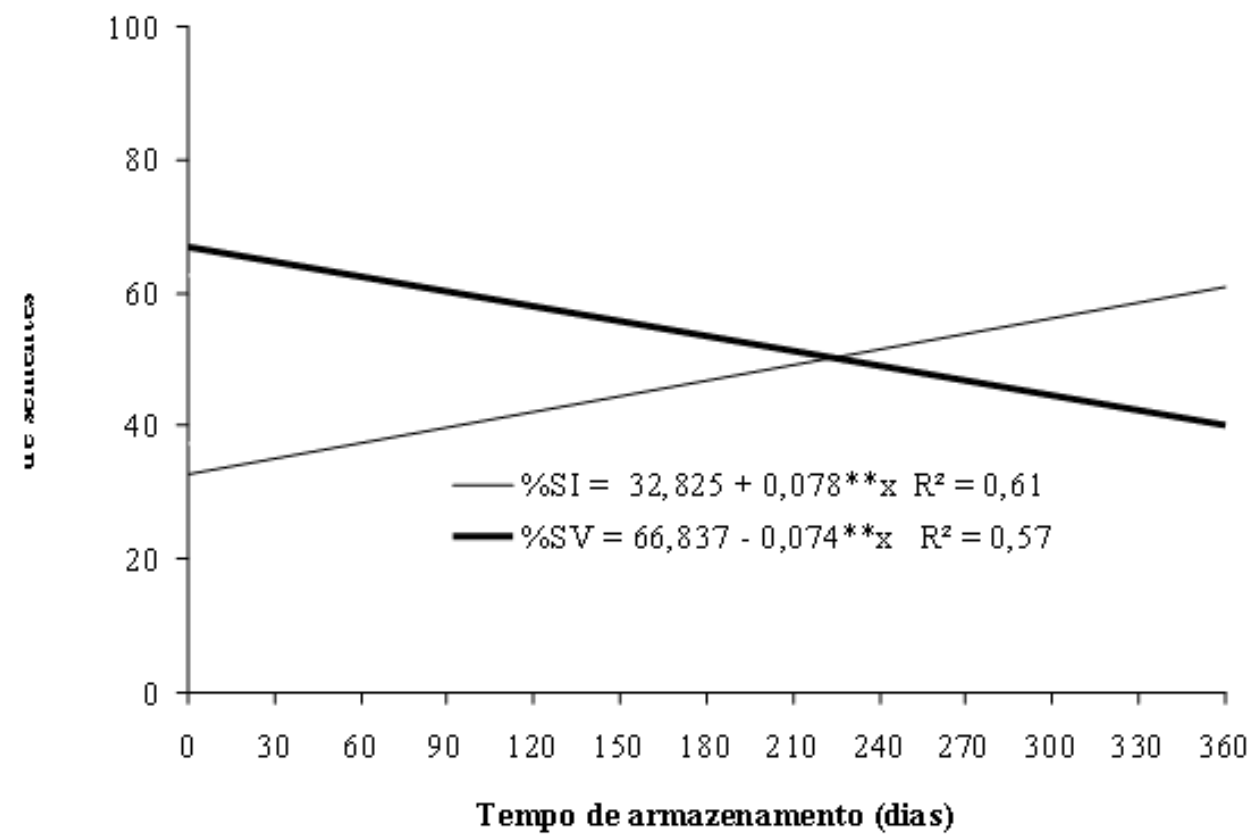

Figura 1.Valores da porcentagem de sementes inviáveis (\%SI) e de sementes viáveis (\%SV) de Brassavola tuberculata Hook. em função do tempo de armazenamento. Dourados-MS, UFGD, 2012.

Figure 1. Values of the percentage of unviable seeds (\% SI) and viable seeds (SV\%) Brassavola tuberculata Hook. as a function of storage time. Dourados-MS, UFGD, 2012.

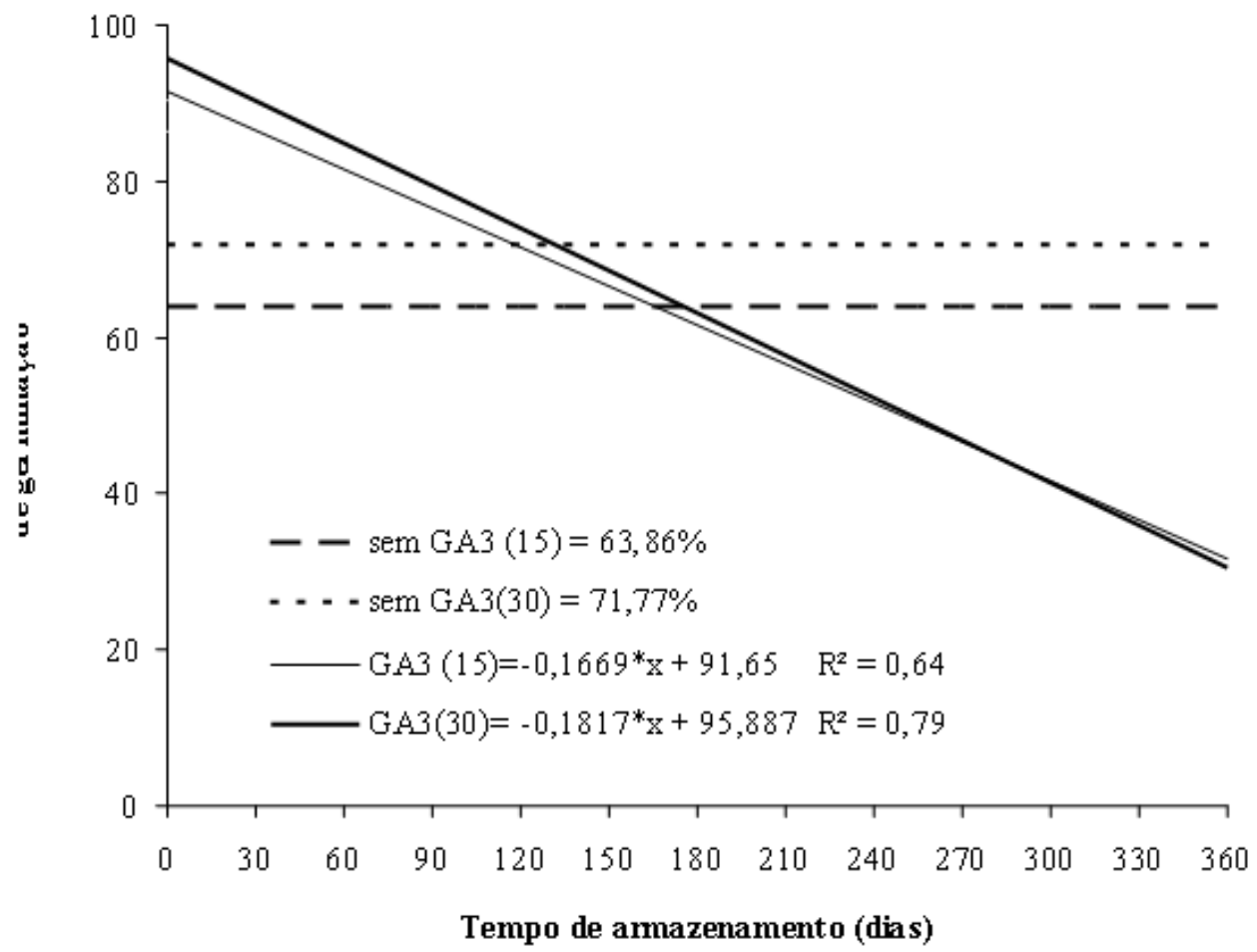

Figura 2. Valores da porcentagem de germinação de Brassavola tuberculata Hook. em função do tempo de armazenamento, do período de cultivo (15 ou 30 dias) e da embebição com GA3 (com e sem embebição). Dourados-MS, UFGD, 2012.

Figure 2. Values of germination percentage of Brassavola tuberculata Hook. as a function of storage time, the culture period (15 or 30 days) and soaking in GA3 (with and without soaking). Dourados-MS, UFGD, 2012. 
dessa sementes também na categoria 1. Entretanto, o mesmo autor salienta que outros dois acessos de Schomburgkia crispa, armazenados nas mesmas condições e pelo mesmo período, apresentaram porcentagem de germinação entre 20 e $40 \%$ e, à semelhança dos resultados observados para B. tuberculata, submetida a tratamento pré-germinativo com $\mathrm{GA}_{3}$ após o armazenamento, não se enquadraram em nenhuma categoria de HARTMANN et al. (1997).

Em relação à tonalidade dos embriões em função da utilização do teste de tetrazólio (Tz) observou-se que a espécie mantém o mesmo padrão de coloração até o final do período de armazenamento. Os resultados do teste para este trabalho apresentaram baixa correlação com os da germinação ( $\mathrm{Tz}$ e 30 dias $=0,51 ; \mathrm{Tz}$ e 15 dias $=0,39 ; \mathrm{Tz}$ e 30 dias $\mathrm{GA}_{3}=0,25 ; \mathrm{Tz}$ e 15 dias $\left.\mathrm{GA}_{3}=0,25\right)$ indicando que o método amostral pode ser utilizado apenas para predizer a viabilidade das sementes, e não a provável porcentagem de germinação das mesmas, uma vez que seus valores foram sempre inferiores aos do teste de germinação.

Esses resultados podem ser decorrentes do fato de que as sementes providas de embriões parcialmente coloridos tenham sido consideradas inviáveis neste estudo. BRASIL (2009) preconiza que embriões parcialmente coloridos possam ser viáveis, já que a posição e o tamanho das áreas necrosadas determinam a viabilidade das sementes. As sementes de orquídeas são muito pequenas, em torno de 0,05 milímetros (ARDITTI e GHANI, 2000), o que dificulta cortes que permitam a visualização do interior do embrião para correta avaliação dos danos em seus tecidos essenciais. Desta forma, sementes que foram consideradas inviáveis podem ter germinado em condições adequadas.

Outro fator que pode ter ocasionado a baixa correlação entre o teste tetrazólio amostral e a porcentagem de sementes germinadas foi a ausência do pré-condicionamento das sementes, uma vez que HOSOMI et al. (2012) relatam que o pré-condicionamento de sementes de Cattleya walkeriana e C. leopoldii, com solução de sacarose a $10 \%$ por 24 horas, permitiu maior identificação de sementes viáveis pelo teste de tetrazólio.

\section{CONCLUSÃO}

Em vista dos resultados observados, pôde-se concluir que: 1) sementes de Brassavola tuberculata podem ser armazenadas por até 360 dias a $5 \pm 1{ }^{\circ} \mathrm{C}$ mantendo a categoria 1 do índice de armazenabilidade de HARTMANN et al. (1997), se não submetidas a tratamento pré-germinativo com $\mathrm{GA}_{3} ; 2$ ) $\mathrm{O}$ tratamento pré-germinativo com $\mathrm{GA}_{3}$ propicia aumento na germinação de sementes $B$. tuberculata armazenadas por até 130 dias; 3) A espécie apresenta maior porcentagem de germinação aos 30 dias de cultivo independente da realização de tratamento pré-germinativo com $\mathrm{GA}_{3}$. 4) O teste de tetrazólio, efetuado de maneira amostral, pode ser utilizado apenas para indicação da viabilidade das sementes armazenadas e não como indicador de percentual de germinação dessa espécie.

\section{REFERÊNCIAS}

ALVAREZ-PARDO; V. M., FERREIRA, A. G. Armazenamento de sementes de orquídeas. Revista Brasileira de
Sementes, Pelotas, v.28, n.1, p.92-98, 2006.

ARDITTI, J.; GHANI, A. K. A. Numerical and physical properties of orchid seeds and their biological implication. New Phytologist, Cambridge, v.145, n.3, p.367-421, 2000.

BACH, E. E.; CASTRO, O. L. Germinação de sementes de Cattleya sp. (Orchidaceae) em cultura de tecido visando produção de mudas. Arquivos do Instituto Biológico, São Paulo, v.71, n.4, p.741-749, 2004.

BARROS, F. De et al. Orchidaceae in Lista de espécies da flora do Brasil. Jardim Botânico do Rio de Janeiro. 2013 (http:// floradobrasil.jbrj.gov.br/jabot/floradobrasil/ FB11230)

BRASIL. Ministério da Agricultura, Pecuária e Abastecimento. Regras para análise de sementes. Brasília: MAPA/ACS, 2009. 399 p.

CAMPOS, D. M. Orquídea: manual prático de reprodução. 3.ed. Rio de Janeiro: Expressão e Cultura, 2002. 143p. DRESSLER, R. L. Phylogeny and classification of the orchid family. Portland: Dioscorides press, 1993. 314p.

EIGELDINGER, O.; MURPHY, L. S. Orchids: a complete guide to cultivation. Nova York: Drake Publishers, 1972. $230 \mathrm{p}$.

FERREIRA, D. F. Sisvar: versão 5.3. Lavras: UFLA, DEX/UFLA, 2010.

FRANÇA NETO, J. B.; KRYZANOWSKI, F. C.; COSTA, N. P. O teste de tetrazólio em sementes de soja. Londrina: EMBRAPA/ CNPSO, 1998. 72p.

FRANÇA NETO, J. B. Teste de tetrazólio para determinação do vigor de sementes. In: KRZYZANOWSKI, F. C., VIEIRA, R. D., FRANÇA NETO, J. B. (Ed.). Vigor de sementes: conceitos e testes. Londrina: ABRATES, 1999. $218 \mathrm{p}$.

HARTMANN, H. T. et al. Plant propagation: principles and pratices. 6. ed. Nova Jersei: Prentice Hall, 1997. 770p.

Hosomi, T. S. et al. Improved assessment of viability in the germination of Cattleya (Orchidaceae) seeds following storage. In Vitro Cellular \& Developmental Biology-Plant, Worldwide, v.48, n.1, p.127-36, 2012

IMES, R. Orchids: the illustrated identifier to over 100 cultivated varieties. London: Apple, 1997. 80p.

JUNQUEIRA, A. H.; PETTZ, M. da S. Mercado interno para os produtos da floricultura brasileira: características, tendências e importância socioeconômica recente. Revista Brasileira de Horticultura Ornamental, Campinas, v.14, n.1, p.37-52, 2008.

KÖPPEN, W. Climatologia: com um estúdio de los climas 
de la tierra. Publications In: Climatology. Laboratory of Climatology, New Gersey, 1948. 104p.

KRZYZANOWISKI, F. C.; VIEIRA, R. D.; FRANÇA NETO, J. B. Vigor de sementes: conceitos e testes. Associação brasileira de tecnologia de sementes. Londrina: ABRATES, 1999. 218p.

MACEDO, M. C. et al. Efeito do ácido giberélico na germinação assimbiótica de sementes de Schomburgkia crispa Lindl. (Orchidaceae). In: CONGRESSO NACIONAL DE BOTÂNICA, 62, Fortaleza. Anais... Fortaleza: UEC, 2011, p.79.

MELlO, C. M. C. Conservação de sementes de orquídeas do Cerrado. Brasília: Universidade de Brasília, 2000. 48 p. Dissertação (Mestrado em Biologia).

MIYOSHI, K.; MII, M. Phytohormone pre-treatment for the enhancement of seed germination and protocorm formation by the terrestrial orchid, Calanthe discolor (Orchidaceae), in asymbiotic culture. Scientia Horticulturae, Wageningen, v.63, n.3-4, p.263-7, 1995.

MURASHIGE T., SKOOG F. A revised medium for rapid growth and bioassays with tobacco tissue cultures. Physiologia Plantarum, Swedwn, v.15, n.3, p.473-497, 1962.

OLIVEIRA, L. M.; CARVALHO, M. L. M.; DAVI-
DE, A. C. Teste de tetrazólio para avaliação de sementes de Peltophorum dubium (Sprengel) Taubert Leguminosae Caesalpinioideae. Cerne, Lavras, v.11, n.2, p.159-166, 2005.

PRITCHARD, H. W.; SEATON, P. T. Orchids seed storage: historical perspective, current status and future prospects for long-term conservation. Selbyana, Sarasota, v.14, p.89-104. 1993.

PRITCHARD, H. W.; POINTER, L. C. A.; SEATON, T. $\mathrm{P}$. Interspecific variation in orchid seed longevity in relation to ultra-dry storage and cryopreservation. Lindleyana, Palm Beach, v.14, n.2, p. 92-101, 1999.

RECH A. R.; ROSA, Y. B. C. J.; ROSA-JUNIOR, E. J. Levantamento e características ecológicas de Orchidaceae da mata ciliar do Rio Dourados, Dourados-MS. Revista Árvore, Viçosa, v.35, n.3, p.717-724, 2011.

SANTOS, G. A. et al.. Utilização de reguladores hormonais na germinação e formação de plântulas in vitro de orquídeas. Maringá: CESUMAR, 2007. p. 07-12. Iniciação Científica.

STEFANELLO, S. et al. Conversão in vitro de raízes e folhas de Miltonia flavescens Lindl. em protocormos e regeneração de plantas. Ciência e Agrotecnologia, Lavras, v.33, p.53-59, 2009. 